\title{
Notes on the vocalizations of Band-tailed Sierra-finch (Phrygilus alaudinus)
}

\section{Peter Boesman}

In the following we briefly analyze and compare voice of the different races of Band-tailed Sierra-finch (Phrygilus alaudinus). We also try to quantify the extent of any vocal differences using the criteria proposed by Tobias et al. (2010), as a support for taxonomic review. We have made use of sound recordings available on-line from Xeno Canto (XC).

An overview of song per region, from north to south, illustrated with sonograms:

Ecuador
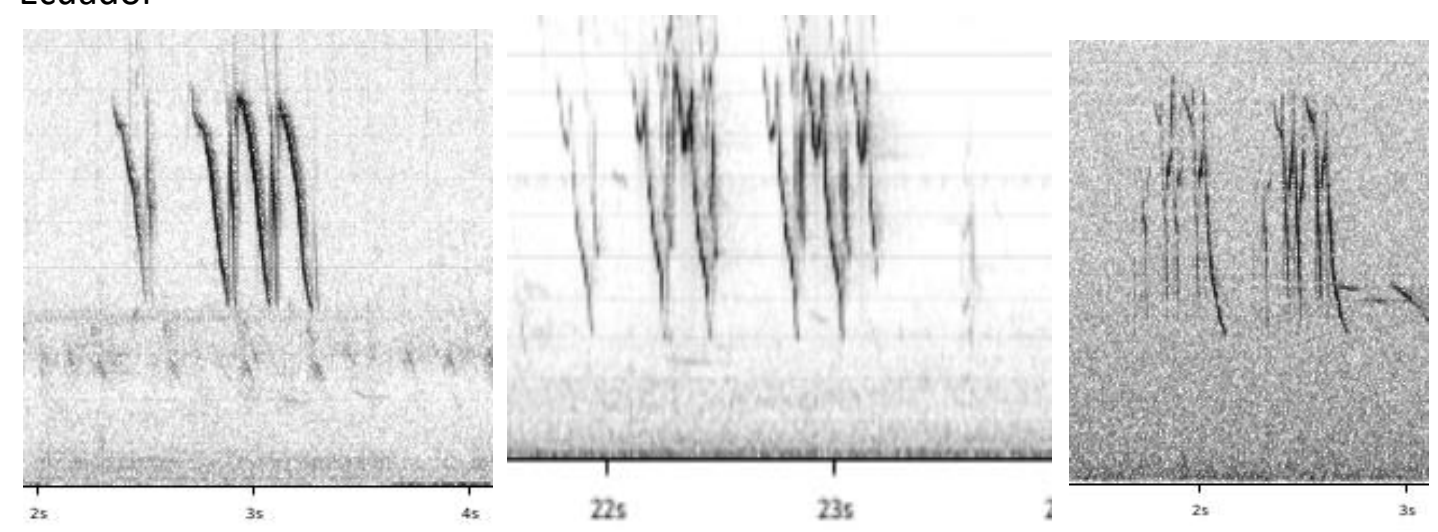

\section{Peru}
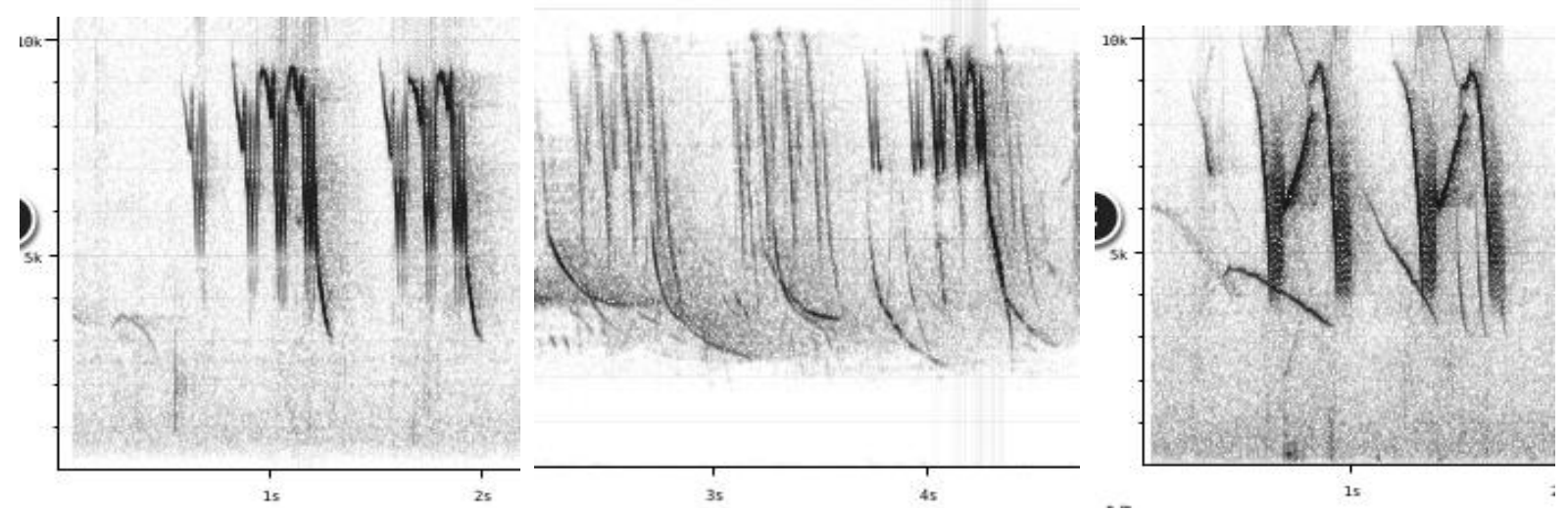

C Bolivia
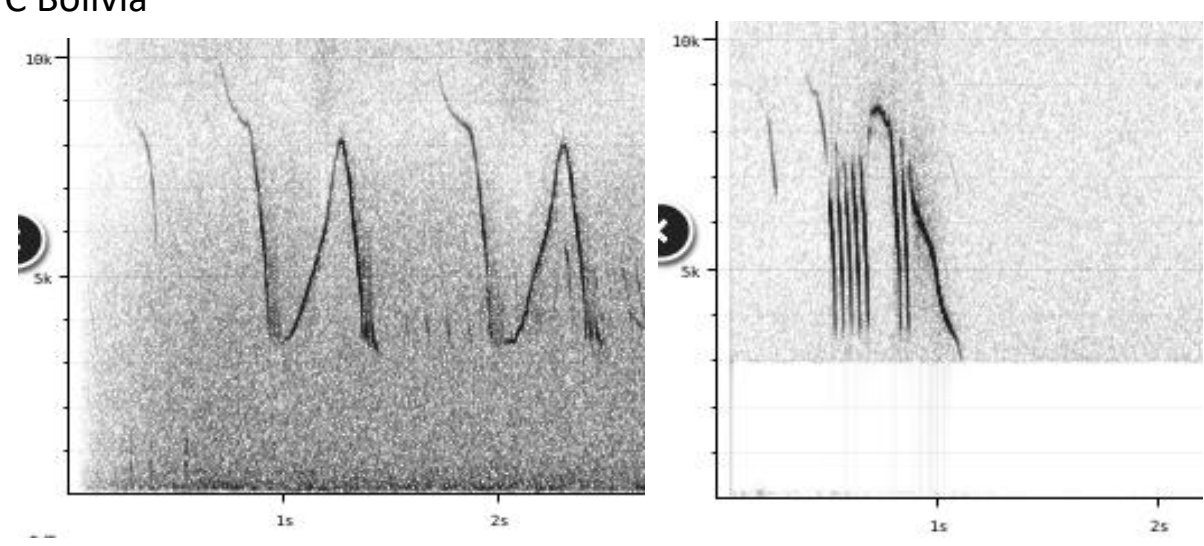

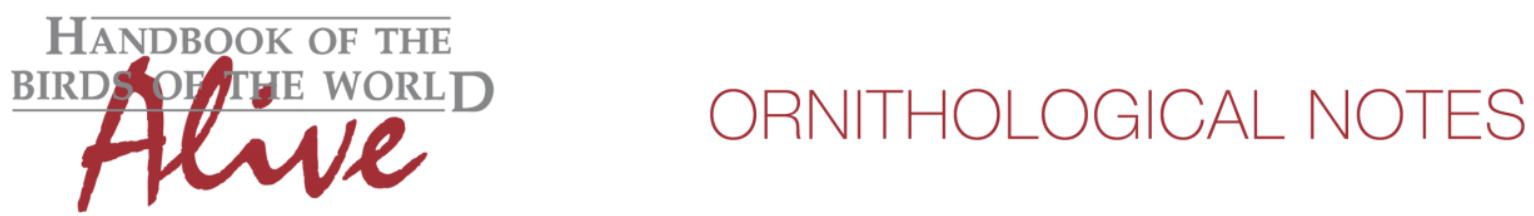

N Argentina

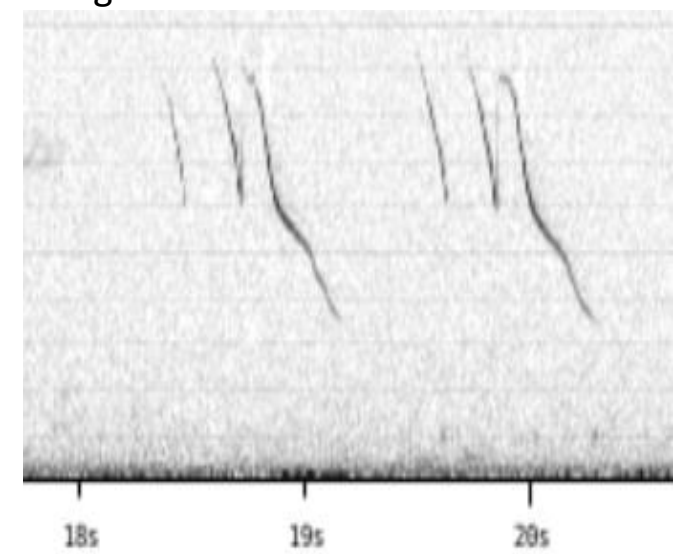

Cordoba region, Argentina

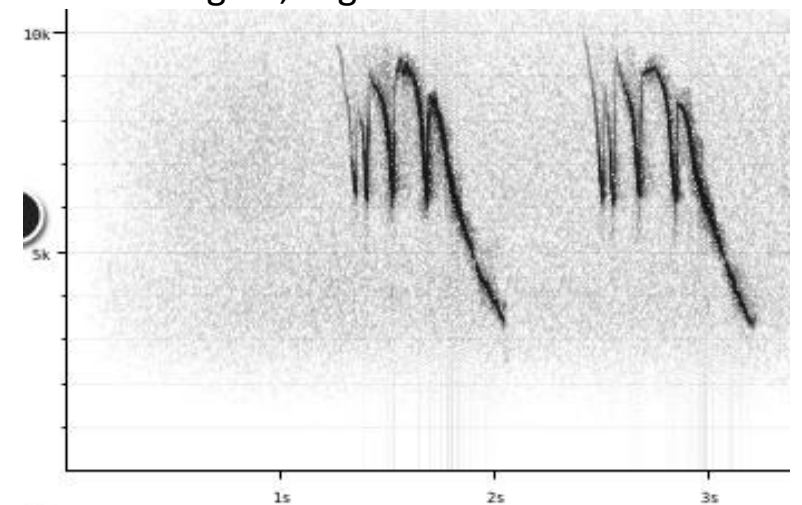

C Chile
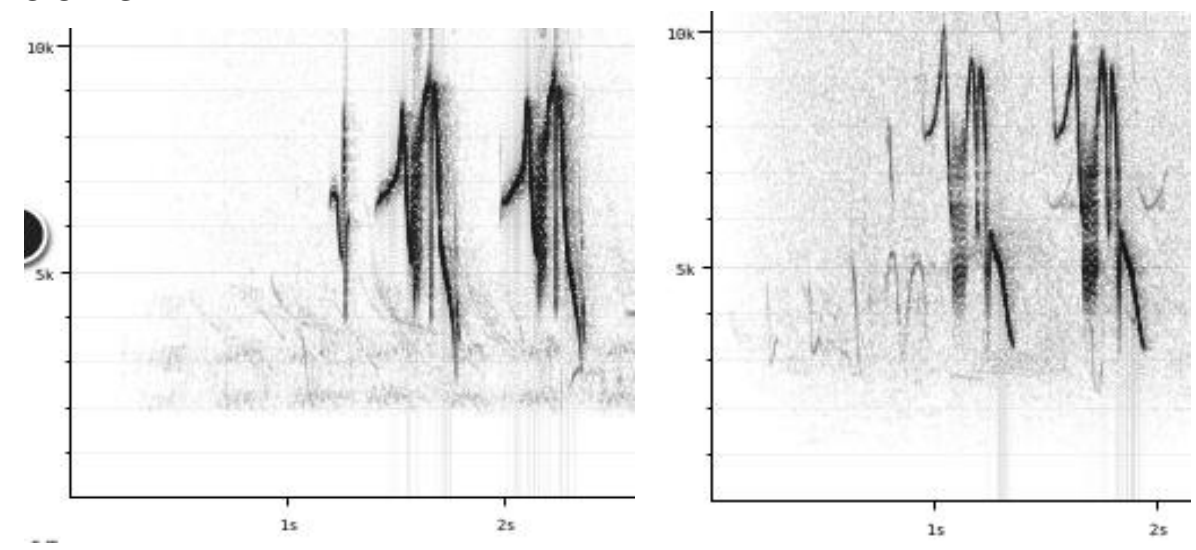

Song of all races is structurally similar: a complex rather piercing note repeated 1-3 times, sometimes preceded by an incomplete note. Note shapes are variable, and it would seem that differences are regional dialects rather than true differences among subspecies.

There is no clear difference between the northern group of smaller and darker races (humboldti, bipartitus, bracki and excelsus) and the southern group of two larger and paler ones (nominate and venturii)). 
This note was finalized on 4th July 2016, using sound recordings available on-line at that moment. We would like to thank in particular the sound recordists who placed their recordings for this species on XC: Israel Aragon, Peter Boesman, Guillermo Egli, Carlos Ferrari, Daniel Gonzalez Amat, Richard Hoyer, Alvaro Jaramillo, Doug Knapp, Niels Krabbe, Dan Lane, Bernabe Lopez-Lanus, John V Moore, Jonas Nilsson and Christian Pinto.

\section{References}

Tobias, J.A., Seddon, N., Spottiswoode, C.N., Pilgrim, J.D., Fishpool, L.D.C. \& Collar, N.J. (2010). Quantitative criteria for species delimitation. Ibis 152(4): 724-746.

\section{Recommended citation}

Boesman, P. (2016). Notes on the vocalizations of Band-tailed Sierra-finch (Phrygilus alaudinus). HBW Alive Ornithological Note 400. In: Handbook of the Birds of the World Alive. Lynx Edicions, Barcelona. (retrieved from http://www.hbw.com/node/1253794 on 2 December 2016). 